\title{
openheart Beta blockers versus calcium channel blockers for provocation of vasospastic angina after drug-eluting stent implantation: a multicentre prospective randomised trial
}

Mitsuaki Sawano (D , , ${ }^{1,2}$ Toshiomi Katsuki, ${ }^{1}$ Takeshi Kitai, ${ }^{3}$ Koichi Tamita, ${ }^{4}$ Kotaro Obunai, ${ }^{5}$ Yukinori Ikegami, ${ }^{6}$ Takafumi Yamane, ${ }^{3}$ Ikuko Ueda, ${ }_{1}^{1}$ Ayaka Endo, ${ }^{7}$ Yuichiro Maekawa, ${ }^{8}$ Akio Kawamura, ${ }^{9}$ Keiichi Fukuda, ${ }^{1}$ Shun Kohsaka ${ }^{1}$

\begin{abstract}
- Additional material is published online only. To view, please visit the journal online (http://dx.doi.org/10.1136/ openhrt-2020-001406).

To cite: Sawano M, Katsuki T, Kitai T, et al. Beta blockers versus calcium channel blockers for provocation of vasospastic angina after drug-eluting stent implantation: a multicentre prospective randomised trial. Open Heart 2020;7:e001406. doi:10.1136/

openhrt-2020-001406
\end{abstract}

MS, TK and SK contributed equally.

Received 29 July 2020 Revised 11 September 2020 Accepted 23 September 2020

Check for updates

(c) Author(s) (or their employer(s)) 2020. Re-use permitted under CC BY-NC. No commercial re-use. See rights and permissions. Published by BMJ.

For numbered affiliations see end of article.

Correspondence to

Dr Shun Kohsaka; sk@keio.jp

\section{ABSTRACT}

Background Drug-eluting stent-induced vasospastic angina (DES-VSA) has emerged as a novel complication in the modern era of percutaneous coronary intervention $(\mathrm{PCl})$. Although beta blockers (BBs) are generally recommended for coronary heart disease, they may promote incidence of DES-VSA. This study aimed to compare the effects of calcium channel blockers (CCBs) perceived to be protective against DES-VSA and BBs on subsequent coronary events after second-generation drug-eluting stent implantation.

Methods In this multicentre prospective, randomised study, 52 patients with coronary artery disease who underwent $\mathrm{PCl}$ for a single-vessel lesion with everolimuseluting stent placement were randomised into poststenting $B B(N=26)$ and $C C B(N=26)$ groups and followed for 24 months to detect any major cardiovascular events (MACE). A positive result on acetylcholine provocation testing during diagnostic coronary angiography (CAG) at 9 months was the primary endpoint for equivalence. MACE included all-cause death, non-fatal myocardial infarction, unstable angina, cerebrovascular disease or coronary revascularisation for stable coronary artery disease after index PCl.

Results At 9 months, 42 patients (80.8\%) underwent diagnostic coronary angiography and acetylcholine provocation testing. Among them, seven patients in each group were diagnosed with definite vasospasm (intentionto-treat analysis $26.9 \%$ vs $26.9 \%$, risk difference 0 $(-0.241,0.241))$. Meanwhile, the secondary endpoint, 24-month MACE, was higher in the CCB group (19.2\%) than in the BB group $(3.8 \%)(p=0.01)$. In detail, coronary revascularisation for stable coronary artery disease was the predominant endpoint that contributed to the greater proportion of MACE in the CCB group (CCB (19.2\%) vs BB $(3.8 \%), p=0.03)$.

Conclusions The incidence of acetylcholine-induced coronary artery spasms did not differ between patients receiving $\mathrm{BBs}$ or CCBs at 9 months after $\mathrm{PCl}$. However, a higher incidence of 2-year MACE was observed in the CCB group, suggesting the importance of $\mathrm{BB}$ administration. Trial registration number This study was registered at the Japanese University Hospital Medical Information

\section{Key questions}

What is already known about this subject?

- Drug-eluting stent-induced vasospastic angina (DES-VSA) has emerged as a novel complication in the contemporary era of percutaneous coronary intervention (PCI). Beta blockers are widely recommended for patients with coronary heart disease; however, they can potentially induce DES-VSA. For prevention of naturally occurring vasospastic angina, calcium channel blockers are recommended which may also offer protection against DES-VSA though evidence is scarce.

What does this study add?

- Occurrence of acetylcholine-induced DES-VSA did not differ at 9 months between beta blocker and calcium channel blocker groups. However, a higher incidence of 2-year repeat revascularisation was observed in the calcium channel blocker group, suggesting the importance of beta-blocker administration.

How might this impact on clinical practice?

- Calcium channel blockers as an alternative to beta blockers for DES-VSA prevention should not be encouraged routinely. Concomitant use of both agents may be suitable for patients who had PCl with suspected or higher risk for coronary endothelial dysfunction, a topic which merits further study.

Network (UMIN) Clinical Trial Registry (The Prospective Randomized Trial for Optimizing Medical Therapy After Stenting: Calcium-Beta Trial; UMIN000008321, https:// upload.umin.ac.jp/cgi-open-bin/ctr_e/ctr_view.cgi? recptno=R000009536).

\section{BACKGROUND}

Beta-blocker (BB) administration for patients with acute myocardial infarction (MI) after 


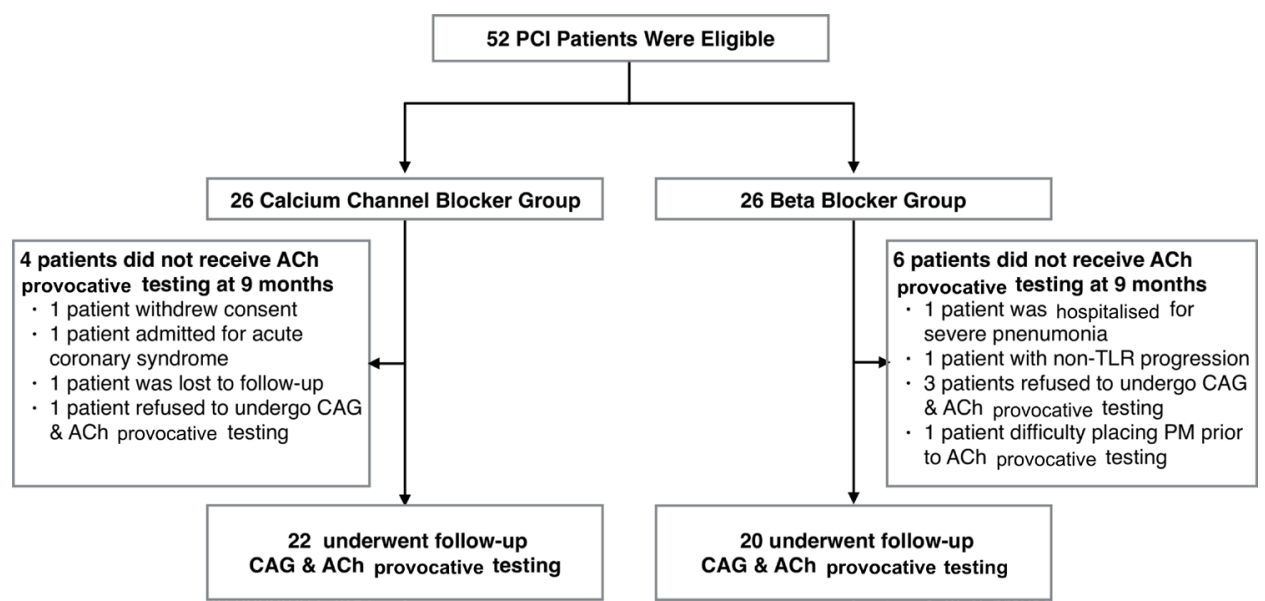

Figure 1 Study population. ACh, acetylcholine; CAG, coronary angiography; PCl, percutaneous coronary intervention; PM, pacemaker; TLR, target lesion revascularisation.

percutaneous coronary intervention (PCI) has been strongly recommended by American and European guidelines ${ }^{1-5}$ based on the results of two large randomised clinical trials, $\beta$-Blocker Heart Attack Trial ${ }^{6}$ and the Norwegian Multicenter Study Group trial, ${ }^{7}$ that demonstrated reductions in infarct size, early mortality and risk of death when continued in the long term. However, its effectiveness has been in doubt over recent years, because many trials supporting the use of BBs were conducted prior to the widespread use of PCI and because the prescription rates of currently accepted optimal medical therapies were significantly lower than in the modern era. ${ }^{8}$ A recent observational study from Medicare beneficiaries suggested limited additional benefits of BBs in patients who were prescribed statins and ACE inhibitors/ angiotensin-receptor blockers for long-term cardiovascular events. ${ }^{9}$ Importantly, in the Western population with stable angina, ${ }^{10}$ a meta-analysis including results from the TIBET ${ }^{11}$ and APSIS trials, ${ }^{12}$ found that the effect of $\mathrm{BB}$ was equivalent in angina reduction, and that the $\mathrm{BB}$ rates of adverse events compared with calcium channel blockers (CCB) or long-acting nitrates lead to different recommendations among the major cardiology societies. Moreover, the risk of BB-induced vasospastic angina (VSA) has been perceived as a potential threat among the VSA-prevalent Japanese population particularly after drug-eluting stent placement. ${ }^{13}$ In Japanese society guideline, patients with coronary artery disease (CAD) presenting with coexisting atherosclerosis and VSA are recommended to start on long-acting CCB for VSA prevention and BBs if only CCBs are concurrently prescribed. ${ }^{14}$ Lastly, drug-eluting stent-induced VSA (DES-VSA) has emerged as a novel complication in the contemporary era of PCI. ${ }^{15} 16$

To study this complication, we compared the effect of BBs and CCBs monotherapy in combination with

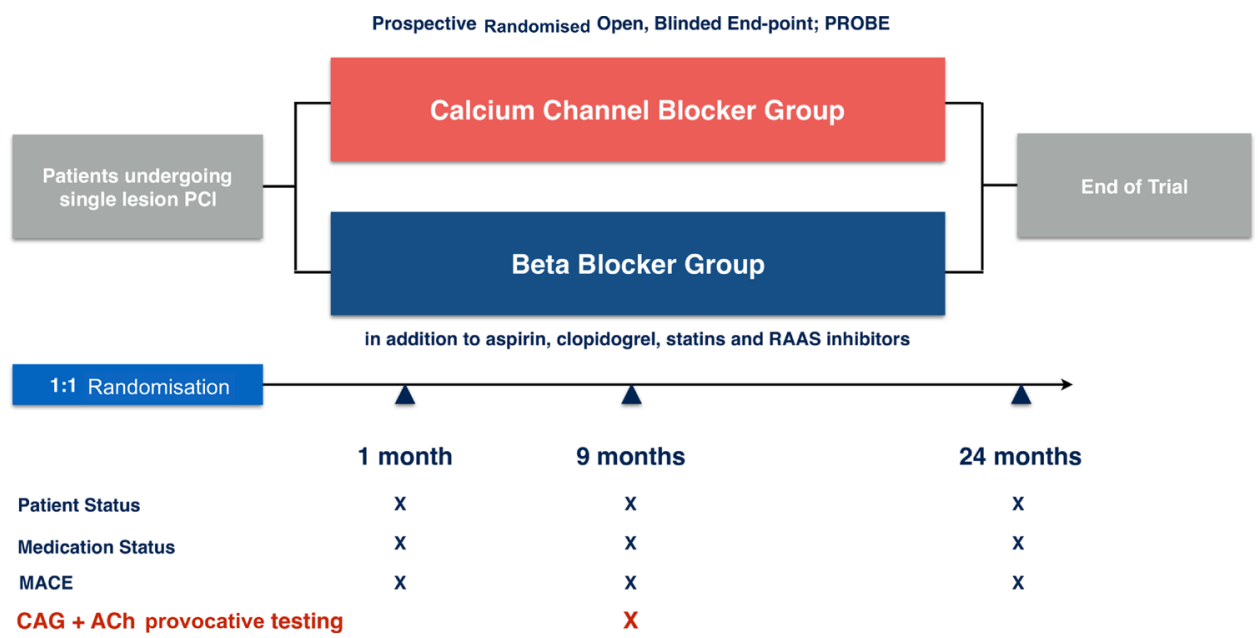

Figure 2 Study design and treatments. The Prospective Randomised Trial for Optimising Medical Therapy After Stenting: Calcium-Beta trial is a prospective, randomised, open-labelled, blinded endpoint clinical trial comparing the effects of calcium channel blocker and beta-blocker administration after second generation drug-eluting stent implantation. Patient data are collected at baseline, 9 months and 24 months after initial PCI marked as X in the figure. ACh, acetylcholine; CAG, coronary angiography; MACE, major cardiovascular events; $\mathrm{PCl}$, percutaneous coronary intervention; $\mathrm{PROBE}$, prospective randomised open blinded end-point; RAAS, renin-angiotensin-aldosterone system. 
Coronary artery disease

Table 1 Baseline characteristics

\begin{tabular}{|c|c|c|c|c|c|}
\hline \multirow[b]{2}{*}{ Number of patients } & \multicolumn{2}{|l|}{ BB } & \multicolumn{2}{|l|}{ CCB } & \multirow[b]{2}{*}{$P$ value } \\
\hline & \multicolumn{2}{|l|}{26} & \multicolumn{2}{|l|}{26} & \\
\hline Age (years) & \multicolumn{2}{|c|}{$67.7 \pm 13.0$} & \multicolumn{2}{|c|}{$65.4 \pm 11.1$} & 0.32 \\
\hline Male (\%) & 81 & 21 & 73 & 19 & 0.47 \\
\hline Body mass index (\%) & \multicolumn{2}{|c|}{$24.1 \pm 3.3$} & \multicolumn{2}{|c|}{$25.5 \pm 4.7$} & 0.24 \\
\hline \multicolumn{6}{|l|}{ Medical history } \\
\hline Myocardial infarction (\%) & 4 & 1 & 15 & 4 & 0.23 \\
\hline Heart failure (\%) & 0 & 0 & 0 & 0 & 0.61 \\
\hline $\mathrm{PCl}$ & $0 \%$ & 0 & $23 \%$ & 6 & 0.02 \\
\hline CABG & $0 \%$ & 0 & $4 \%$ & 1 & 0.30 \\
\hline Diabetes mellitus & $27 \%$ & 7 & $27 \%$ & 7 & 0.81 \\
\hline Haemodialysis & $0 \%$ & 0 & $0 \%$ & 0 & 0.32 \\
\hline Cerebrovascular disease & $12 \%$ & 3 & $4 \%$ & 1 & 0.36 \\
\hline Peripheral vascular disease & $8 \%$ & 2 & $4 \%$ & 1 & 0.51 \\
\hline Chronic lung disease & $0 \%$ & 0 & $0 \%$ & 0 & 0.32 \\
\hline Hypertension & $73 \%$ & 19 & $62 \%$ & 16 & 0.40 \\
\hline Smoking & $12 \%$ & 3 & $12 \%$ & 3 & 0.61 \\
\hline Dyslipidaemia & $69 \%$ & 18 & $65 \%$ & 17 & 0.99 \\
\hline Atrial fibrillation & $4 \%$ & 1 & $0 \%$ & 0 & 0.37 \\
\hline \multicolumn{6}{|l|}{$\mathrm{PCl}$ indications } \\
\hline Unstable angina & $19 \%$ & 5 & $27 \%$ & 7 & \multirow[t]{3}{*}{0.22} \\
\hline Stable angina & $62 \%$ & 16 & $46 \%$ & 12 & \\
\hline Asymptomatic/atypical & $19 \%$ & 5 & $23 \%$ & 6 & \\
\hline \multicolumn{6}{|l|}{ Location of PCl lesion } \\
\hline Left circumflex & $19 \%$ & 5 & $27 \%$ & 7 & \multirow[t]{3}{*}{0.16} \\
\hline Right coronary artery & $23 \%$ & 6 & $8 \%$ & 2 & \\
\hline Left anterior descending & $54 \%$ & 14 & $62 \%$ & 16 & \\
\hline Bifurcation lesion & $12 \%$ & 3 & $31 \%$ & 8 & 0.14 \\
\hline Type C lesion & $46 \%$ & 12 & $19 \%$ & 5 & 0.048 \\
\hline Chronic total occlusion lesion & $27 \%$ & 7 & $4 \%$ & 1 & 0.02 \\
\hline Previous stenting to target lesion & $0 \%$ & 0 & $4 \%$ & 1 & 0.03 \\
\hline
\end{tabular}

BB, beta blocker; CABG, coronary artery bypass grafting; CCB, calcium channel blocker; $\mathrm{PCl}$, percutaneous coronary intervention.

other optimal medical therapy in this prospective, multicentre, open-labelled, randomised trial; we evaluated angiography-confirmed acetylcholine (ACh)-induced VSA at 9 months as a surrogate for DES-VSA; and evaluated major adverse cardiac and cerebrovascular events (MACE) at 24 months as the secondary endpoint.

\section{METHODS \\ Design}

This prospective, open-labelled, two-armed randomised clinical trial for optimising medical therapy after stenting compared the efficacy of CCBs and BBs for the prevention of VSA after second-generation DES implantation (figure 1). The study overview was reported to the Japanese University Hospital Medical Information Network prior to patient recruitment and is available online. The current trial enrolled patients aged $\geq 20$ years, who had stable/unstable angina or silent ischaemia, and who underwent PCI for a single-vessel lesion with the Xience (Abbott Vascular, Santa Clara, California, USA) or Promus (Boston Scientific, Natick, Massachusetts, USA) everolimus-eluting stent (EES) placement. The assigned medical treatments were titrated to maximally tolerated doses of amlodipine (CCB) $10 \mathrm{mg}$ daily or bisoprolol (BB) $10 \mathrm{mg}$ daily. The incidences of ACh-induced VSA in both arms were compared at 9 months after EES implantation for elective cases.

All patients provided written informed consent before participation. The trial was conducted in accordance with the principles of the Declaration of Helsinki and adheres to Consolidated Standards of Reporting Trials guidelines. All data were collected from health records via a secure 


\begin{tabular}{|c|c|c|c|c|c|}
\hline \multirow[b]{2}{*}{ Number of patients } & \multicolumn{2}{|l|}{ BB } & \multicolumn{2}{|l|}{ CCB } & \multirow[b]{2}{*}{$P$ value } \\
\hline & 26 & & 26 & & \\
\hline Aspirin & $92 \%$ & 24 & $96 \%$ & 25 & 1 \\
\hline Clopidogrel & $92 \%$ & 24 & $96 \%$ & 25 & 1 \\
\hline Anticoagulation use & $0 \%$ & 0 & $8 \%$ & 2 & \\
\hline Warfarin & $0 \%$ & 0 & $4 \%$ & 1 & 1 \\
\hline Rivaroxaban & $0 \%$ & 0 & $4 \%$ & 1 & 1 \\
\hline ACEi/ARB & $42 \%$ & 11 & $46 \%$ & 12 & 1 \\
\hline BB & $77 \%$ & 20 & $12 \%$ & 3 & $<0.001$ \\
\hline Carvedilol & $0 \%$ & 0 & $4 \%$ & 1 & \\
\hline Bisoprolol & $73 \%$ & 19 & $4 \%$ & 2 & \\
\hline Propranolol & $4 \%$ & 1 & $0 \%$ & 0 & \\
\hline \multicolumn{6}{|l|}{ CCB } \\
\hline Amlodipine & $15 \%$ & 4 & $77 \%$ & 20 & $<0.001$ \\
\hline Statin & $85 \%$ & 22 & $73 \%$ & 19 & 0.42 \\
\hline Atorvastatin & $12 \%$ & 3 & $15 \%$ & 4 & \\
\hline Pitavastatin & $19 \%$ & 5 & $12 \%$ & 3 & \\
\hline Pravastatin & $4 \%$ & 1 & $0 \%$ & 0 & \\
\hline Rosuvastatin & $50 \%$ & 13 & $46 \%$ & 12 & \\
\hline Other lipid-lowering agents & $4 \%$ & 1 & $12 \%$ & 3 & 0.70 \\
\hline
\end{tabular}

Values are mean_SD or $\mathrm{n}(\%)$.

ACEi, ACE inhibitor; ARB, angiotensin II receptor blocker ; BB, beta blocker; CCB, calcium channel blocker.

electronic database capture system from each participating hospital. Data were entered by dedicated clinical research coordinators or trained physicians deployed from Keio University Hospital.

\section{Subjects}

The exclusion criteria included a history of stent restenosis or coronary bypass surgery, previous diagnosis of VSA within 1 year and/or on treatment, previous PCI within 1 year, an acute MI within 7 days, left main trunk lesion, left ventricular ejection fraction of $<35 \%$, and previous pacemaker implantation or atrioventricular block more than first degree. Additional exclusions were, systolic blood pressure $<100 \mathrm{~mm} \mathrm{Hg}$ or a heart rate $<60$ beats per minute prior to $\mathrm{PCI}$, renal failure with a serum creatinine level $>2.0 \mathrm{mg} / \mathrm{dL}$ or on haemodialysis, liver failure (eg, diagnosis of cirrhosis), asthma-chronic obstructive lung disease overlap, diagnosis of malignancy within 5 years, or pregnancy, and patients with $\geq 4$ EES placements.

Eligible patients were randomly assigned centrally, in a 1:1 ratio by simple randomisation based on computer-generated numbers to receive either $\mathrm{CCB}$ or $\mathrm{BB}$; additionally patients received within 24 hours of the baseline PCI optimal medical therapy (aspirin, P2Y12 inhibitor, statin and renin-angiotensin-aldosterone system inhibitor). EESs were implanted with $\leq 3$ stents after a pre-dilation procedure, and at the predilation site and culprit or severely stenotic coronary lesions (greater than $75 \%$ stenosis). All patients were administered oral aspirin (100 mg/day) and clopidogrel for at least 2 days before PCI, which was continued during the 24-month follow-up period.

The BB group was instructed to receive bisoprolol as a cardioselective $\beta 1$-adrenergic blocking agent at an initial dose of $1.25 \mathrm{mg}$ and titrated up to $5 \mathrm{mg}$ per day as tolerated. Those patients already on a different type of BB shifted to the equivalent amount of bisoprolol as follows: carvedilol 5 $\mathrm{mg}$ to bisoprolol $1.25 \mathrm{mg}$, atenolol $25 \mathrm{mg}$ to bisoprolol 2.5 $\mathrm{mg}$ and propranolol $80 \mathrm{mg}$ to bisoprolol $5 \mathrm{mg}$, accordingly. The treating physicians were instructed to maintain the highest tolerable dose of $\mathrm{BB}$ during the trial. Similarly, the $\mathrm{CCB}$ group was instructed to receive amlodipine at an initial dose of $1.25 \mathrm{mg}$ and titrated up to $10 \mathrm{mg}$ per day as tolerated. The optimised medical therapy was adjusted by the treating physicians as needed.

The patients were followed at 1, 9 and 24 months after hospital discharge in the outpatient clinic of each participating hospital by the treating physicians (figure 2).

\section{Outcomes}

At 9 months after the initial PCI, we performed ACh provocation testing for positive vasospasm: we recorded the following three conditions and considered their occurrence as positive signs of ACh-induced VSA :(1) transient, total or subtotal coronary artery occlusion of $>90 \%$ stenosis, (2) typical anginal-type with chest discomfort and (3) ischaemic ECG changes (ST segment elevation $\geq 0.1 \mathrm{mV}$, ST segment depression $\geq 0.1 \mathrm{mV}$ or a new appearance of negative U-wave in at least two contiguous leads). ACh provocation testing was evaluated using 20 $\mu \mathrm{g}$ and $50 \mu \mathrm{g}$ titration dosing of ACh for the right coronary artery, and 20, 50 and $100 \mu \mathrm{g}$ for the left coronary artery complying with the current Japanese Circulation Society Guidelines. ${ }^{14}$

\section{Sample size}

We estimated that the assignment of 106 patients (53 patients for each of the $\mathrm{BB}$ and $\mathrm{CCB}$ arms) would provide $80 \%$ power at a one-sided alpha level of 0.05 to show the equivalence of $\mathrm{CCB}$ to $\mathrm{BB}$ with respect to the 9-month primary endpoint, with an equivalence margin of 0.05 for the upper $95 \%$ confidence limit for the between-group difference in event rates, assuming a $30 \%$ event rate in the $\mathrm{BB}$ group and a $15 \%$ event rate in the CCB group based on previous studies. ${ }^{17}$

Patient enrolment was terminated prematurely prior to reaching the planned sample size of 106 because of slow enrolment. The study sample size was reduced to 52 patients (26 patients in each group) to hold $80 \%$ power with an equivalence margin of 0.13 for the upper $95 \%$ confidence limit for the between-group difference in event rates, assuming a $30 \%$ event rate in the $\mathrm{BB}$ group and a $15 \%$ event rate in the CCB group. During the time between patient randomisation and follow-up coronary angiography $(\mathrm{CAG})$, four patients in the $\mathrm{CCB}$ group and six in the BB group dropped out due to withdrawal of consent, a major cardiovascular event refusal to 
undergo CAG and ACh provocation testing, or were lost to follow-up.

\section{Statistical analysis}

All principal analyses were performed with data from the time of randomisation in the intention-to-treat population, which included all patients according to the group to which they were randomly assigned, regardless of the treatment received. Equivalence was calculated with the Farrington and Manning method, ${ }^{18}$ and sensitivity analyses were performed in the per-protocol population. Categorical variables were compared using the $\mathrm{X}^{2}$ test or Fisher's exact test. Continuous variables were compared using the Student's t-test or Wilcoxon rank-sum test for non-normally distributed data. All statistical analyses were performed using R V.3.4.3 with packages tidyverse V.1.2.1. for variable selection and ratesci V.0.3-0 for calculating, approximate Bayesian CIs.

\section{RESULTS}

From August 2012 to May 2015, 52 patients (CCB group, $\mathrm{n}=26$; $\mathrm{BB}$ group, $\mathrm{n}=26$ ) were enrolled. Patient demographic, coronary lesions and procedural characteristics were basically similar and were well balanced between the two groups (table 1) (online supplemental table 1).

Notably, there were fewer patients in the BB group than in the CCB group with a history of PCI $(0 \%$ vs $23 \%$ $\mathrm{p}=0.02)$ or previous stenting to the target lesion $(0 \%$ vs $4 \% \mathrm{p}=0.03)$, and more patients with type $\mathrm{C}$ lesions $(46 \%$ vs $19 \% \mathrm{p}=0.048)$ and chronic total occlusion PCI (27\% vs $4 \% \mathrm{p}=0.024)$ (table 2).

At the time of 1-month visit post-discharge, the randomised medications were prescribed to 24/26 $(92.3 \%)$ in the BB group and 24/26 (92.3\%) in the CCB group (online supplemental table 2). At 9 months after PCI, $42(84.6 \%)$ patients underwent follow-up CAG and ACh stress testing. The primary outcome of definite vasospasm occurred in seven patients (intention-to-treat analysis, 26.9\%; per-protocol analysis, $31.8 \%$ ) in the CCB group and seven patients (intention-to-treat analysis, 26.9\%; per-protocol analysis, $35.0 \%$ ) in the BB group (table 3).

The risk difference point estimate and 95\% CIs calculated by the Farrington and Manning method were 0 $(-0.241$ to 0.241$)$ under the intention-to-treat analysis and $0.0318(-0.317,0.254)$ under the per-protocol analysis, both

\begin{tabular}{|c|c|c|c|c|c|}
\hline \multirow[b]{2}{*}{ Number of patients } & \multicolumn{2}{|l|}{ BB } & \multicolumn{2}{|l|}{ CCB } & \multirow[b]{2}{*}{$P$ value } \\
\hline & 26 & & 26 & & \\
\hline \multicolumn{6}{|l|}{ Positive Ach-induced spasm } \\
\hline Intention-to-treat analysis & $26.9 \%$ & 7 & $26.9 \%$ & 7 & 1 \\
\hline Per-protocol analysis & $35 \%$ & 7 & $31.8 \%$ & 7 & 0.21 \\
\hline \multicolumn{6}{|l|}{ Coronary angiographic findings } \\
\hline $75 \%$ spasm & $8 \%$ & 2 & $4 \%$ & 1 & 0.71 \\
\hline $90 \%$ spasm & $15 \%$ & 4 & $15 \%$ & 4 & \\
\hline 99\% spasm & $23 \%$ & 6 & $27 \%$ & 7 & \\
\hline $100 \%$ spasm & $4 \%$ & 1 & $0 \%$ & 0 & \\
\hline QCA & 3.25 & & 19.5 & & 0.04 \\
\hline Improvement with nitroglycerin administration & $46 \%$ & 12 & $42 \%$ & 11 & 0.34 \\
\hline Chest discomfort & $42 \%$ & 11 & $46 \%$ & 12 & 0.27 \\
\hline Typical chest discomfort during test & $27 \%$ & 7 & $27 \%$ & 7 & 0.89 \\
\hline \multicolumn{6}{|l|}{ Time required for symptom alleviation (minutes) } \\
\hline Under 5 & $42 \%$ & 11 & $58 \%$ & 15 & 0.48 \\
\hline Above 5 & $23 \%$ & 6 & $4 \%$ & 1 & \\
\hline Ambiguous or unknown & $35 \%$ & 9 & $27 \%$ & 7 & \\
\hline ECG change during provocation & $46 \%$ & 12 & $27 \%$ & 7 & 0.18 \\
\hline Non-specific STT change & $0 \%$ & 0 & $8 \%$ & 2 & 0.23 \\
\hline ST elevation $>0.5 \mathrm{~mm}$ & $15 \%$ & 4 & $8 \%$ & 2 & \\
\hline ST depression $>0.5 \mathrm{~mm}$ & $31 \%$ & 8 & $15 \%$ & 4 & \\
\hline \multicolumn{6}{|l|}{ Time required for ECG recovery (minutes) } \\
\hline Under 5 & $31 \%$ & 8 & $19 \%$ & 5 & 0.54 \\
\hline Above 5 & $15 \%$ & 4 & $8 \%$ & 2 & \\
\hline
\end{tabular}

Values are mean_SD or $\mathrm{n}(\%)$.

Ach, acetylcholine; BB, beta blocker; CCB, calcium channel blocker; QCA, quantitative coronary analysis. 
Table 4 Secondary endpoints at 24 months

\begin{tabular}{|c|c|c|c|c|c|}
\hline \multirow[b]{2}{*}{ Number of patients } & \multicolumn{2}{|l|}{ BB } & \multicolumn{2}{|l|}{ ССВ } & \multirow[b]{2}{*}{$\mathbf{P}$ value } \\
\hline & 26 & & 26 & & \\
\hline \multicolumn{6}{|l|}{ MACE } \\
\hline Intention to treat & $3.8 \%$ & 1 & $19.2 \%$ & 5 & 0.01 \\
\hline Per-protocol & $5.0 \%$ & 1 & $13.6 \%$ & 3 & 0.1 \\
\hline \multicolumn{6}{|l|}{ Individual endpoints of MACE } \\
\hline All-cause death & $0 \%$ & 0 & $0 \%$ & 0 & NA \\
\hline Hospitalisation for non-fatal MI and unstable angina & $0 \%$ & 0 & $0 \%$ & 0 & NA \\
\hline Coronary revascularisation for stable CAD & $4 \%$ & 1 & $19 \%$ & 5 & 0.03 \\
\hline CVD & $0 \%$ & 0 & $0 \%$ & 0 & NA \\
\hline Bleeding complication & $0 \%$ & 0 & $0 \%$ & 0 & NA \\
\hline Severe side effects due to medication & $0 \%$ & 0 & $4 \%$ & 1 & 0.18 \\
\hline
\end{tabular}

Values are mean_SD or $\mathrm{n}(\%)$.

$\mathrm{BB}$, beta blocker; CAD, coronary artery disease; CCB, calcium channel blocker; CVD, cerebrovascular disease; MACE, major adverse cardiac events; MI, myocardial infarction; NA, not applicable.

demonstrating inconclusive results due to CIs wider than the equivalence margin set as 0.13 (adjusted ORs shown in online supplemental table 3). Meanwhile, the secondary endpoint, 24-month MACE, was higher in the CCB group $(19.2 \%)$ than in the BB group (3.8\%) ( $\mathrm{p}=0.01)$. In detail, coronary revascularisation for stable $\mathrm{CAD}$ was the predominant endpoint that contributed to the greater proportion of MACE in the CCB group (CCB (19.2\%) vs BB (3.8\%), $\mathrm{p}=0.03)($ table 4$)$.

\section{DISCUSSION}

To study the novel complication of DES-VSA, in this prospective, multicentre, open-labelled, randomised trial, we compared the effect of BBs and CCBs on angiographyconfirmed ACh-induced VSA at 9 months as a surrogate for DES-VSA. We found that the incidence of ACh-induced VSA among patients randomly receiving BB was not inferior to CCB at the 9-month angiography, in addition to other optimal medical therapies, they received after the initial PCI. Notably, CCB administration was associated with a higher incidence of coronary revascularisation for stable CAD at 24 months than BB administration.

In this study, BBs did not significantly increase the incidence of ACh-induced VSA, compared with CCBs, in contrast to the common belief regarding VSA. Nishigaki et al have demonstrated the effectiveness of CCB in 'spontaneous' VSA prevention in a meta-analysis. Four major CCBs, benidipine, amlodipine, nifedipine and diltiazem, were shown to suppress recurrent spontaneous VSA attacks, with benidipine showing the most beneficial effect on longterm MACE. ${ }^{19}$ Our results showed that BBs are certainly as effective compared with CCBs for VSA prevention after EES implantation, which is believed to be a risk factor for VSA among patients with non-obstructive CAD.

Conversely, we found that BBs do not essentially increase the incidence of VSA among the Japanese population compared with CCB administration. Importantly, we observed a trend in a higher incidence of 24-month hospitalisation for stable $\mathrm{CAD}$ in the $\mathrm{CCB}$ group, suggesting the presence of protective effects provided by BB. Although this may be due to the higher proportion of patients with a history of $\mathrm{PCI}$ and previous stenting, this is an important finding since post-PCI BB administration on discharge, particularly in East Asians, has been reported to be lower than that in Western countries. ${ }^{20-22}$ This is based on previous observational studies reporting a vulnerability in the occurrence of spontaneous VSA as well as DES-VSA after PCI. In a prospective observational study, Kohno et alstudied 615 consecutive patients with VSA-suspected CAD undergoing ACh provocation testing, including those with and without previous PCI; they reported that patients with a history of PCI were significantly associated with higher risks of positive results on provocation; although, its relationship was not illustrated in terms of spontaneous and DES-VSA separately. ${ }^{23}$ Moreover, these patients were less likely to receive BBs on discharge, although, a higher proportion of these patients presented with unstable angina.

Previous trials have shown mixed results regarding the efficacy of CCBs on DES-VSA and incident MACE. Moreover, these have not been compared with the efficacy of BBs, except in the Japanese Beta-blockers and Calcium Antagonists Myocardial Infarction Study conducted in the pre-DES era. ${ }^{24}$ The study did not show any significant difference between the BB and CCB groups. In the first-generation DES era, Terashima et al demonstrated that telmisartan, an angiotensin II receptor blocker, significantly reduces the incidence of ACh-induced VSA compared with amlodipine after coronary DES implantation. ${ }^{17}$ In our study, approximately $40 \%$ of the patients received optimal medical therapy after PCI, including angiotensin-receptor blockers, in both arms, and the proportions did not differ significantly. More recently, in the second-generation DES era, the Nifedipine on Coronary Vascular Function after Drug-Eluting Stent Implantation (NOVEL) Study, ${ }^{25}$ found that nifedipine was effective for DES-VSA prevention compared with that in 
patients without $\mathrm{CCB}$ or $\mathrm{BB}$ administration in patients with stable CAD who had EES implantations to the left anterior descending artery 8-10 months prior to follow-up CAG. Among the 50 patients receiving nifedipine in the NOVEL Study, 38 patients underwent follow-up CAG with ACh provocation testing and $9(23.7 \%)$ patients presented with DESVSA; this was slightly lower than the present study results. The higher than expected DES-VSA observed in the CCB group may have been caused by difference in patient selection and study protocol resulting in higher proportion of patients with a history of PCI or previous stenting to the target lesion in the CCB group.

This trial has several limitations. First, the current trial was underpowered to detect equivalence for the primary endpoint because of the reduced final sample size owing to slow patient enrolment. Although BBs were not inferior to $\mathrm{CCB}$, the number of patients with the positive ACh response, seven in each group, was small. Therefore, the current trial results may be 'inconclusive', warranting future, larger-scale studies. Second, the pathophysiology of clinically observed DES-induced vasospasms may differ from that of vasospasms observed during ACh provocation testing. High concentrations of ACh infused into the coronary artery may have overly diagnosed subclinical DES-VSA as those observed in the real world. Also, ACh provocative testing prior to PCI was not performed. Third, although randomisation was successful for other clinical features, there were fewer patients in the BB group with a history of PCI or prior stenting to the target lesion and more patients with type $\mathrm{C}$ lesions, including chronic total occlusion. These factors may have led to a higher incidence of 24-month MACE in the CCB group, mainly driven by elective PCI hospitalisations; although, the exact indications and characteristics of the treated coronary lesions are unknown. Fourth, we did not study the concomitant use of both agents, which may be suitable for patients who had PCI with suspected, or higher risk for coronary endothelial dysfunction. Fifth, the recent findings from the 2020 International Study of Comparative Health Effectiveness with Medical and Invasive Approaches trial have questioned the need for PCI in patients with stable angina with moderate or more subjectively proven myocardial ischaemia, ${ }^{26}$ however, our protocol and enrolment was registered in 2012. Sixth, because this study challenges the conventional use of CCB in DES-VSA by suggesting BBs may be equally effective, replicating this study for validation may be difficult: (1) criteria for PCI has become more restrictive for stable angina since this protocol was started in 2012; (2) obtaining informed consent for voluntary cardiac catheterisation in Western countries may be more challenging than in Japan with its cultural differences.

\section{CONCLUSION}

In this study of novel complication of DES-VSA, no significant difference in the incidence of ACh-induced coronary artery spasms was observed for routine administration of BBs compared with routine CCB administration in elective patients who had PCI who underwent EES implantation in a DES-VSA-vulnerable Japanese population.
Author affiliations

${ }^{1}$ Department of Cardiology, Keio University School of Medicine, Shinjuku-ku, Tokyo, Japan

${ }^{2}$ Department of Cardiology, Tokyo Dental College Ichikawa General Hospital, Ichikawa, Japan

${ }^{3}$ Department of Cardiovascular Medicine, Kobe City Medical Center General Hospital, Kobe, Japan

${ }^{4}$ Department of Cardiology, Nishinomiya Watanabe Cardiovascular Center, Nishinomiya, Hyogo, Japan

${ }^{5}$ Department of Cardiology, Tokyo Bay Urayasu Ichikawa Medical Center, Ichikawa, Japan

${ }^{6}$ Department of Cardiology, National Hospital Organisation Tokyo Medical Center, Meguro-ku, Tokyo, Japan

${ }^{7}$ Department of Cardiology, Saiseikai Central Hospital, Minato-ku, Tokyo, Japan

${ }^{8}$ Division of Cardiology, Internal Medicine III, Hamamatsu University School of Medicine, Hamamatsu, Shizuoka, Japan

${ }^{9}$ Department of Cardiology, International University of Health and Welfare Faculty of Medicine Graduate School of Medicine, Narita, Chiba, Japan

\section{Twitter Mitsuaki Sawano @MitsuakiSawano}

Acknowledgements The authors thank the members of the cardiac catheterisation laboratories of the participating centres and the clinical research coordinators: YM, Shunsuke Yuasa, Hideaki Kanazawa, Kentaro Hayashida and Takashi Kawakami (Keio University School of Medicine); Yukihiko Momiyama, Munehisa Sakamoto, Jun Fuse, Kojiro Tanimoto, Yl and Kohei Inagawa (National Hospital Organization Tokyo Medical Center).

Contributors IU, AE and SK conceived and designed the research. MS and TK performed the statistical analysis. AE and SK handled funding and supervision. TK, KT, KO, YI, TY, IU, YM and AK acquired the data. MS, TK and SK drafted the manuscript. TK, YM, AK and KF made critical revision of the manuscript for key intellectual content. All authors have approved the final article.

Funding This study was supported in part by the grants-in-aid from the Ministry of Health, Labour, and Welfare (Award number: 24790538) and Pfizer Japan Inc. (Tokyo, Japan; award number: 04-013-0455), based on the research contract between the company and the Keio University School of Medicine. SK has received grants from Bayer Yakuhin and Daiichi-Sankyo, lecture fees from Bayer Yakuhin and BristolMyers Squibb, and consulting fees from Pfizer. The equipment and drugs used in the study were purchased by the participating hospitals.

Competing interests MS reports grants from Japan Promotional Society for Cardiovascular Disease Sakakibara Memorial Research Grant, grants from Japan Heart Foundation Japan Heart Foundation Research Grant, and grants from Japan Society for the Promotion of Science Grants-in-Aid for Scientific Research (18K17332) during the conduct of the study; grants from Takeda Pharma, Takeda Japan Medical Office Funded Research Grant 2018 outside the submitted work. TI has a research grant from Boston Scientific. SK reports investigator-initiated grant funding from Bayer and Daiichi Sankyo and personal fees from Bayer and Bristol-Myers Squibb. HI receives lecture fees from Astellas Pharma, AstraZeneca, Bayer, Bristol-Myers Squibb Chugai Pharma, Daiichi Sankyo, Otsuka Pharma, Pfizer, Mochida Pharma and MSD.

Patient consent for publication Not required.

Ethics approval The institutional review boards at each participating hospital approved the trial protocol: Keio University Hospital, Kobe City Medical Center General Hospital, Nishinomiya Watanabe Cardiovascular Center, Tokyo Bay Urayasu Ichikawa Medical Center, National Hospital Organization Tokyo Medical Center and Saiseikai Central Hospital.

Provenance and peer review Not commissioned; externally peer reviewed.

Data availability statement Data are available according to the 'Act on the Protection of Personal Information' Law (as of May 2017) and the 'Ethical Guidelines for Medical and Health Research Involving Human Subjects' (as of March 2015). The current study data were obtained from the JCD-KiCS PCI registry and are available upon request to The Institutional Review Board of Keio University School of Medicine (med-rinri-jimu@adst.keio.ac.jp).

Open access This is an open access article distributed in accordance with the Creative Commons Attribution Non Commercial (CC BY-NC 4.0) license, which permits others to distribute, remix, adapt, build upon this work non-commercially, and license their derivative works on different terms, provided the original work is properly cited, appropriate credit is given, any changes made indicated, and the use is non-commercial. See: http://creativecommons.org/licenses/by-nc/4.0/. 
ORCID iD

Mitsuaki Sawano http://orcid.org/0000-0003-2789-1758

\section{REFERENCES}

1 Antman EM, Anbe DT, Armstrong PW, et al. ACC/AHA guidelines for the management of patients with ST-elevation myocardial infarction: a report of the American College of Cardiology/American heart association Task force on practice guidelines (Committee to revise the 1999 guidelines for the management of patients with acute myocardial infarction). Circulation 2004;110:e82-292.

2 O'Gara PT, Kushner FG, Ascheim DD, et al. 2013 ACCF/AHA guideline for the management of ST-elevation myocardial infarction: a report of the American College of cardiology Foundation/American heart association Task force on practice guidelines. Circulation 2013;127:e362-425.

3 Amsterdam EA, Wenger NK, Brindis RG, et al. 2014 AHA ACC guideline for the management of patients with non-ST-elevation acute coronary syndromes: a report of the American College of Cardiology/American heart association Task force on practice guidelines. Circulation 2014;130:e344-426.

4 Finn SD, Gardin JM, Abrams J, et al. 2012 ACCF/AHA/ACP/AATS/ PCNA/SCAI/STS guideline for the diagnosis and management of patients with stable ischemic heart disease: a report of the American College of cardiology Foundation/American heart association Task force on practice guidelines, and the American College of physicians, American association for thoracic surgery, preventive cardiovascular nurses association, Society for cardiovascular angiography and interventions, and society of thoracic surgeons. Circulation 2012;126:e354-471.

5 Ibanez B, James S, Agewall S, et al. 2017 ESC guidelines for the management of acute myocardial infarction in patients presenting with ST-segment elevation: the task force for the management of acute myocardial infarction in patients presenting with ST-segment elevation of the European Society of cardiology (ESC). Eur Heart J 2018;39:119-77.

6 A randomized trial of propranolol in patients with acute myocardial infarction. I. mortality results. JAMA 1982;247:1707-14.

7 Pedersen TR. The Norwegian multicenter study of timolol after myocardial infarction. Circulation 1983;67:149-53.

8 Borden WB, Redberg RF, Mushlin Al, et al. Patterns and intensity of medical therapy in patients undergoing percutaneous coronary intervention. JAMA 2011;305:1882-9.

9 Korhonen MJ, Robinson JG, Annis IE, et al. Adherence tradeoff to multiple preventive therapies and all-cause mortality after acute myocardial infarction. J Am Coll Cardiol 2017;70:1543-54.

10 Heidenreich PA, McDonald KM, Hastie T, et al. Meta-Analysis of trials comparing beta-blockers, calcium antagonists, and nitrates for stable angina. JAMA 1999;281:1927-36.

11 Dargie HJ, Ford I, Fox KM. Total ischaemic burden European trial (Tibet). Effects of ischaemia and treatment with atenolol, nifedipine $\mathrm{SR}$ and their combination on outcome in patients with chronic stable angina. The Tibet Study Group. Eur Heart J 1996;17:104-12.
12 Forslund L, Hjemdahl P, Held C, et al. Prognostic implications of results from exercise testing in patients with chronic stable angina pectoris treated with metoprolol or verapamil. A report from the angina prognosis study in Stockholm (APSIS). Eur Heart $J$ 2000;21:901-10.

13 Shibutani H, Akita Y, Matsui Y, et al. The potential hazard of drugeluting stent-induced coronary vasospasm causing subacute stent thrombosis: a case report. BMC Cardiovasc Disord 2016;16:236.

14 JCS Joint Working Group. Guidelines for diagnosis and treatment of patients with vasospastic angina (coronary spastic angina) (JCS 2013). Circ J 2014;78:2779-801.

15 Brott BC, Anayiotos AS, Chapman GD, et al. Severe, diffuse coronary artery spasm after drug-eluting stent placement. J Invasive Cardiol 2006;18:584-92.

16 Minami $Y$, Kaneda $\mathrm{H}$, Inoue $\mathrm{M}$, et al. Endothelial dysfunction following drug-eluting stent implantation: a systematic review of the literature. Int J Cardiol 2013;165:222-8.

17 Terashima M, Kaneda H, Nasu K, et al. Protective effect of telmisartan against endothelial dysfunction after coronary drugeluting stent implantation in hypertensive patients. JACC Cardiovasc Interv 2012;5:182-90.

18 Farrington CP, Manning G. Test statistics and sample size formulae for comparative binomial trials with null hypothesis of non-zero risk difference or non-unity relative risk. Stat Med 1990;9:1447-54.

19 Nishigaki K, Inoue Y, Yamanouchi Y, et al. Prognostic effects of calcium channel blockers in patients with vasospastic angina--a meta-analysis. Circ J 2010;74:1943-50.

20 Yasuda S, Nakao K, Nishimura K, et al. The current status of cardiovascular medicine in Japan - analysis of a large number of health records From a nationwide claim-based database, JROADDPC. Circ J 2016;80:2327-35.

$21 \mathrm{Ni} \mathrm{Z}$, Dardas L, Wu B, et al. Cardioprotective medication adherence among patients with coronary heart disease in China: a systematic review. Heart Asia 2019;11:e011173.

22 Won H, Suh Y, Kim GS, et al. Clinical impact of beta blockers in patients with myocardial infarction from the Korean National health insurance database. Korean Circ J 2020;50:499-508.

23 Kohno T, Kohsaka S, Ueda I, et al. Frequency and safety of intracoronary acetylcholine provocation testing compared to coronary interventions: analysis of a contemporary Japanese multicenter PCI registry. Int J Cardiol 2015;183:171-2.

24 Japanese beta-Blockers and Calcium Antagonists Myocardial Infarction (JBCMI) Investigators. Comparison of the effects of beta blockers and calcium antagonists on cardiovascular events after acute myocardial infarction in Japanese subjects. Am J Cardiol 2004;93:969-73.

25 Tsuburaya R, Takahashi J, Nakamura A, et al. Beneficial effects of long-acting nifedipine on coronary vasomotion abnormalities after drug-eluting stent implantation: the novel study. Eur Heart $J$ 2016;37:2713-21.

26 Maron DJ, Hochman JS, Reynolds HR, et al. Initial invasive or conservative strategy for stable coronary disease. N Engl J Med 2020;382:1395-407. 